\title{
Machining of Wood as a Natural Composite Material
}

\author{
Karol VASILKO, Zuzana MURČINKOVÁ
}

\begin{abstract}
In the paper, the wood as natural fibre-layered composite is used to study the principles of effect in machining of such composites and provide the suggestion how to eliminate the unwanted effects in composite material cutting. The suggestion is not in special tool geometry, cutting tool material, toolpath strategy etc. but is based on basically different principle of machining. The actual research in cutting of composites is focused on orthogonal cutting as $2 \mathrm{D}$ process. We have to take into account the $3 \mathrm{D}$ behaviour of chip forming, as the workpiece material is non-homogeneous and directionally oriented. Thus, we studied the idea of so-called free cutting or cutting by straight cutting edge. The principles of such cutting were tested on wood as natural fibre - layered composite and the results are presented in the paper.
\end{abstract}

Keywords: maximum height of profile; natural composite; straight cutting edge; tool tip radius

\section{INTRODUCTION}

The research of principles of the composites cutting is topical despite the nature of composite components fabrication, which is significantly different from the standard designed materials such as metals and alloys. For obtaining final geometry of the composites parts, machining operations such as edge trimming or drilling are often necessary [1].

A greater difficulty of machining is caused by anisotropic directionally oriented material properties of composites, alternating stiff fibre and soft matrix in toolpath, complex damage behaviour in cutting, high abrasiveness etc. Thus, the chip formation and cutting conditions are complicated. In general, the composites are of low machinability [2].

The main unwanted effect in composite cutting is surface damage by delamination, burning or cracks, rapid tool wear, accuracy affected by debonding, subsurface damage and bouncing back phenomenon of workpiece material [3]. The mentioned effects can cause premature failures of components made of composites. In present research, the approaches avoiding unwanted effects have been developed, e.g. by use of the vibrating cutting tool, use of special cutting materials (e.g. polycrystal diamond), use of specially shaped cutting tool etc.

The character of tree trunk anatomy is close to fibre composite structure organized in cylindrical layers. Naturally, the basic wood composition can vary in microscale depending on cell size, grain pattern (straight, wavy, irregular, interlocked) etc. The cells are reinforcing elements of composite and they can be of different shapes. The predominant shape is fibre-microfibrils (about 100 times larger than diameter $[4,8])$. The shorter cells of fibrous shape and of small number are tracheids and parenchyma cells.

Finally, the specific gravity of wood is also important physical property regarding application as well as machining. In case of high specific gravity, the wood strength is also high and it is difficult to machine material [8].

The paper focuses on the turning using the turning tool based on idea of straight cutting edge and developing this idea to specially designed cutting tool.

\section{CUTTING BY NON-STRAIGHT CUTTING EDGE}

The non-straight cutting edge is of either curved or broken line shape. The research and development in the field of cutting tools came to use rounded tooltip and thus the cutting edge is not straight and includes, mostly, the radius. In cutting by non-straight cutting edge, the speed of individual elements of the cut material moves perpendicular to the cutting edge (Fig. 1). The resultant direction of chip flow speed $\left(v_{\mathrm{t}}\right)$ is not perpendicular to the cutting edge. That means that the process of plastic deformation is most complicated in tooltip. The force of cutting resistance is significant.

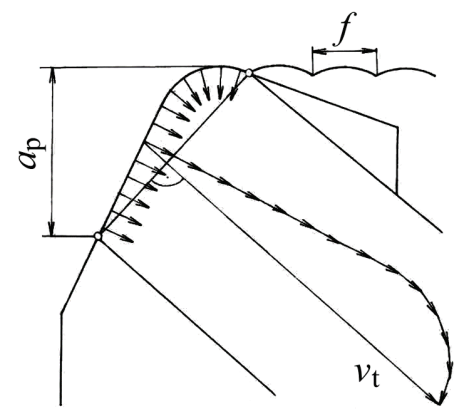

Figure 1 Cutting tool of non-straight cutting (up) and estimation of the resultant direction of chip flow speed vector $v_{\mathrm{t}}\left(a_{\mathrm{p}}\right.$-cut depth, $f-$ feed $)$

The mentioned facts characterizing cutting by the nonstraight cutting edge are inappropriate for cutting of composites of fibre and/or layered structure since the complicated conditions in chip formation are even more complicated by the in-homogeneity of composite.

\section{CUTTING BY STRAIGHT CUTTING EDGE}

Major significant indicator of surface quality is surface roughness $[6,7]$. It is well-known that by increasing the tool tip radius $r_{\varepsilon}$, the quality of machined surface increases. This statement is confirmed by a standard theoretical equation for the determination of the maximum height of the machined surface profile $R z$ :

$$
R z=\frac{f^{2}}{8 r_{\varepsilon}}
$$


where $f$ is feed and $r_{\varepsilon}$ is tool tip radius.

A tool with the infinite radius of cutting edge, it means the straight cutting edge, is a limit case of increasing the radius of tooltip. The turning principle with such a tool is shown in Fig. 2. The tool is inclined by the angle $\lambda_{\mathrm{s}}$. The cutting edge is placed non-parallel to the workpiece axis. It is possible to implement bidirectional tool feed.

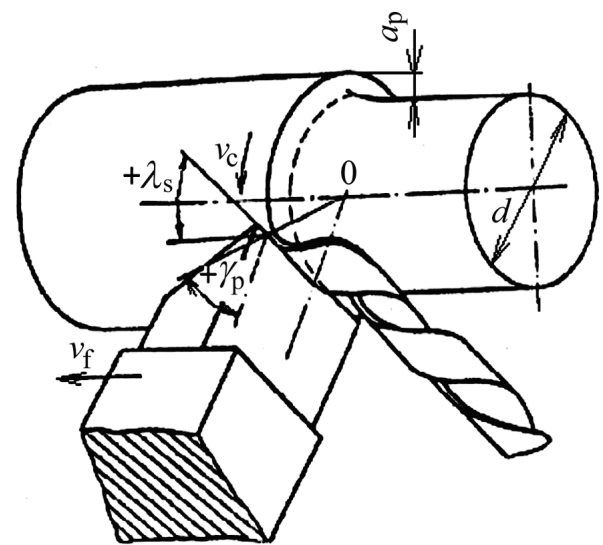

Figure 2 Scheme of turning by straight cutting edge tool, inclined by angle $\lambda_{\mathrm{s}}$

In comparison with the tools with tip radius (nonstraight cutting edge), the length of the engaged cutting edge is much greater.

\section{TURNING OF A NATURAL FIBRE-LAYERED COMPOSITE}

One of the cutting tools with straight cutting edge for experimental tests of turning the wood as a natural fibrelayered composite material is presented in Fig. 3. When the cutting tool becomes worn out it is possible to twist the cutting insert to a new position by use of the fixing screw. Even the worn out inserts from previous classical turning can be used for turning by straight cutting edge.

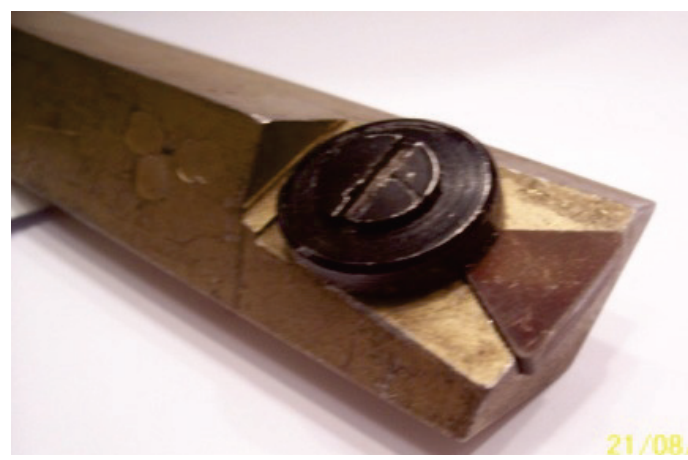

Figure 3 Cutting tool with straight cutting edge

Fig. 4 shows the experimental dependence of the maximum height of profile $R z$ on cutting speed in the range $50-170 \mathrm{~m} / \mathrm{min}$ obtained during turning of wooden (natural composite) workpiece. The decrease of $R \mathrm{z}$ is significant in the range of used cutting speeds. Fig. 4 involves also the graph of the typical performance of non-straight cutting edge tool of tool tip radius $r_{\varepsilon}=0,5 \mathrm{~mm}$ in order to compare $R z$ for both cutting tools. Turning by the straight cutting edge, the cutting speed affects the $R z$ values minimally. This is one of the unique benefits. Similar result was obtained for turning of different kinds of wood (beech, apple, cherry wood etc.).

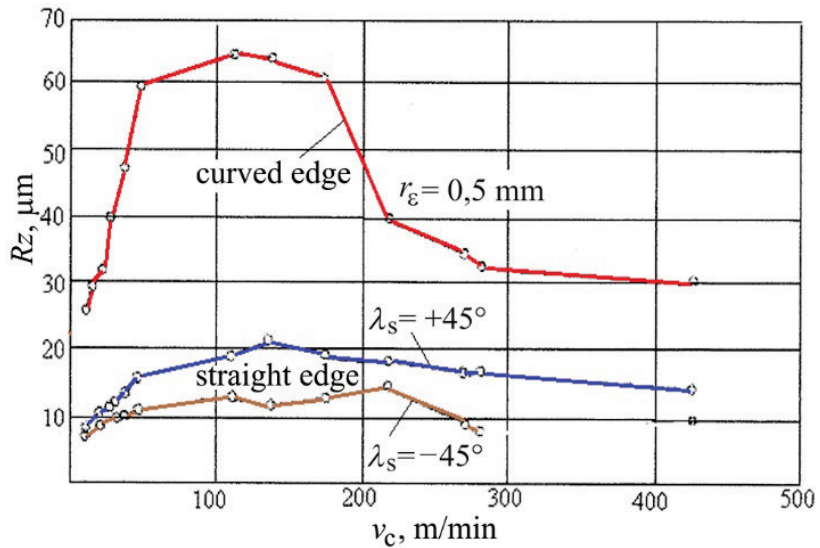

Figure 4 Experimental comparison of $R z=f\left(v_{\mathrm{c}}\right)$ for straight and curved cutting edges, horn beam wood, $a_{\mathrm{p}}=0,5 \mathrm{~mm}, f=0,3 \mathrm{~mm}$, tool: sintered carbide SK $\mathrm{P} 20$

In addition to the improvement of machined surface roughness, the straight cutting edge enables to use much larger feeds $f$ (Fig. 5). Comparing the $R z$ values of feed rate e.g. $f=0.6 \mathrm{~mm}$, in case of non-straight (curved, $r_{\varepsilon}=0,4$ $\mathrm{mm}$ ) cutting edge $R z$ is $116 \mu \mathrm{m}$, in case of straight cutting edge $R z$ is $30 \mu \mathrm{m}$ (more than 4-times lower roughness, better quality).

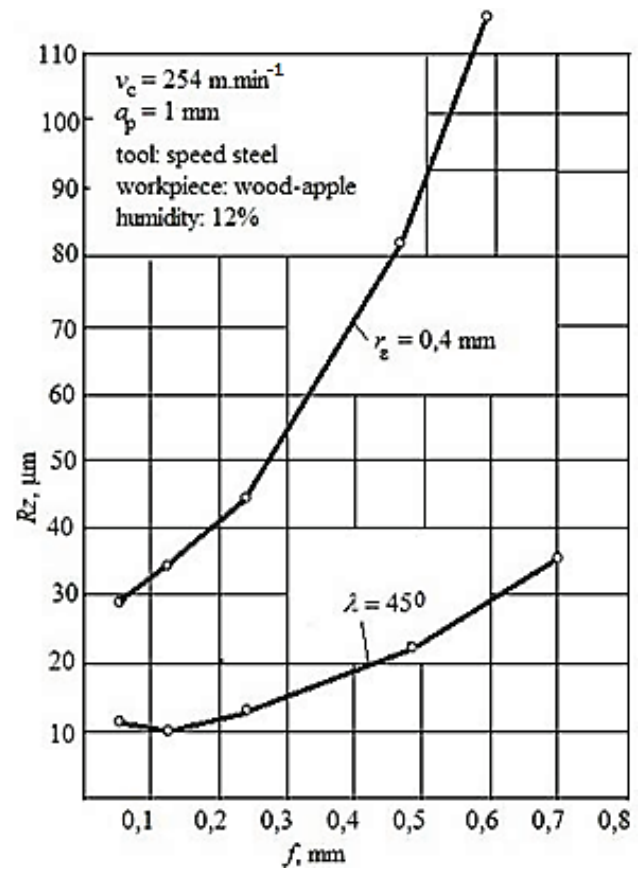

Figure 5 Experimental dependence of $R z=f(f)$ for straight and curved cutting edges, apple-tree wood, $a_{\mathrm{p}}=1 \mathrm{~mm}, v_{\mathrm{c}}=254 \mathrm{~m} / \mathrm{min}$, tool: high-speed steel

The plastic deformation observed on the upper part of the chip in Fig. 6, up, is similar to that of steel chip. Fig. 6, down, schematically presents the orientation of cut regarding the growth rings, forming the concentric layers, and longitudinal fibres in the heartwood. In this case, the wood chip compression is $k=4$.

The comparison of the material ratio curves is also interesting as their character is different. The experimental measurements indicate that increasing the tool tip radius, 
the material ratio is also increasing. This makes the component performance of higher quality.

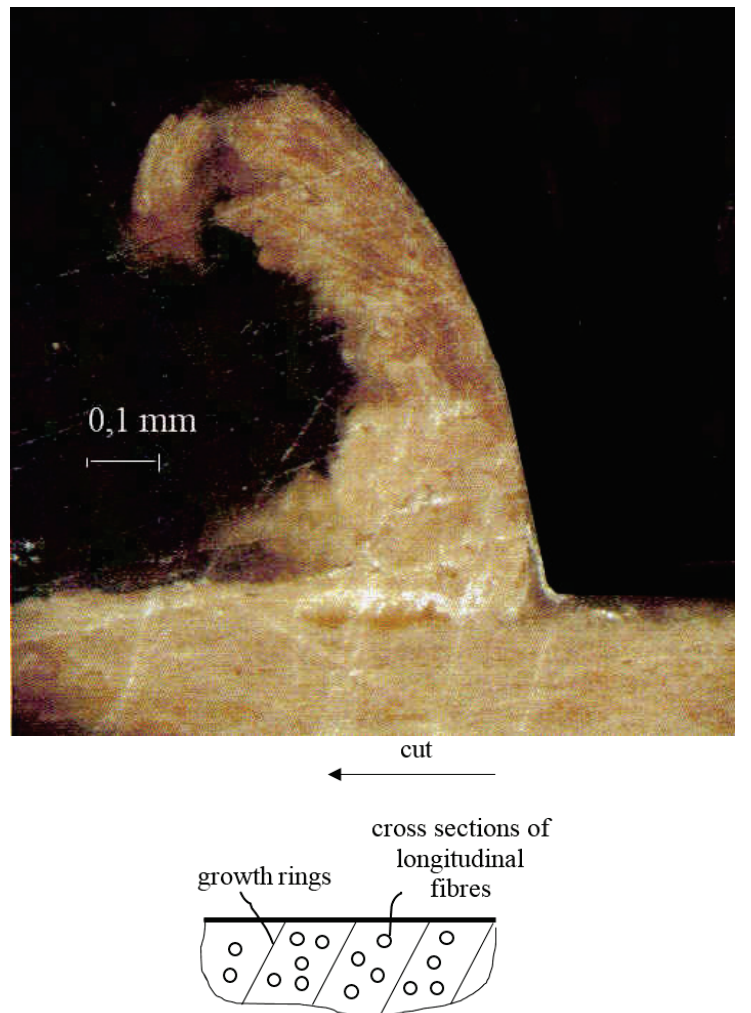

Figure 6 Wooden chip root (up), schema of wood fibre-layered structure (down), cutting speed $100 \mathrm{~m} / \mathrm{min}$

\subsection{The Bowl-Shaped Rotating Tool}

The quality of machined surface, mainly the roughness, improves with increased tool tip radius. The special bowl-shaped rotating cutting tool with large (quasistraight) cutting edge radius was designed and made in 1980 for applications in bearing production (more in [8]), Fig. 7. We used such cutting tool for turning of wood to observe and confirm our previous statements in chapter 3 and 4 . The cutting edge of bowl-shaped rotating cutting tool is of large radius (quasi-straight) and the mechanics of turning is similar to that of straight cutting tool.

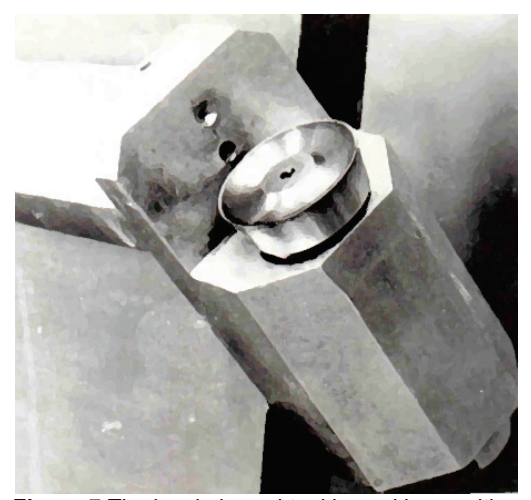

Figure 7 The bowl-shaped tool in working position

The design of the bowl-shaped rotating cutting tool is based on a special conical plain bearing with circumferential groove for oil. The rotation makes the oil moving up. The oil returns through a central hole to the bottom of the housing. The tool is driving by the tangential velocity $v_{\mathrm{t}}$ and the friction force. Fig. 8 shows the bowlshaped rotating tool in the process of turning of the wooden workpiece.

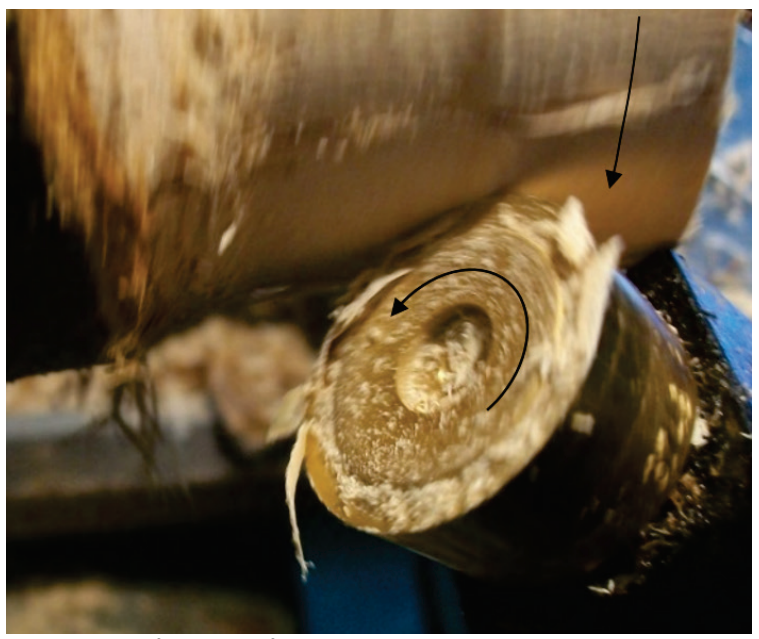

Figure 8 Performance of rotating bowl-shaped tool in turning the wood

The cutting tool can rotate driven either by the velocity of cutting or by the external drive (in Fig. 8 without external drive). Moreover, the cutting tool can be oriented so that the cutting edge inclination angle $\lambda_{\mathrm{s}}$ is positive or negative (Fig. 9). An immediate active section of cutting edge which is in engagement with the workpiece is under the level of workpiece axis. If the rake angle equals zero, the face working angles will be negative at every point of active cutting edge (Fig. 9, up). Fig. 9, down, illustrates an opposite case. Moreover, Fig. 9 presents the velocity vector components addition where $v_{\mathrm{f}}$ is velocity of feed, $v_{\mathrm{t}}$ is tangential velocity of rotating tool, $v_{\mathrm{w}}$ is tangential velocity of workpiece and $v_{\mathrm{c}}$ is cutting speed.
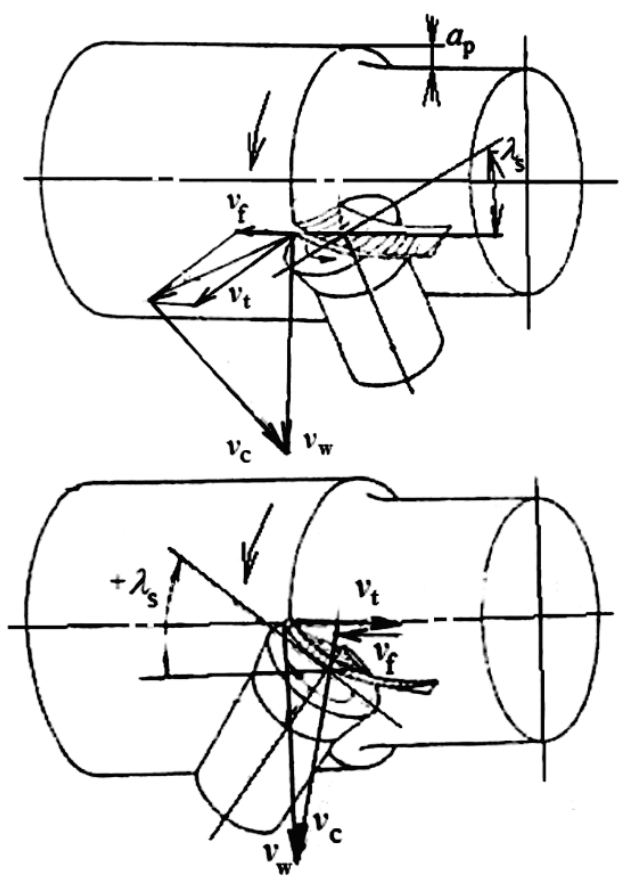

Figure 9 Turning with the bowl-shaped rotating cutting tool of negative (up) and positive angle of cutting edge inclination $\lambda_{\mathrm{s}}$

To determine the maximum height of profile $R z$, it is necessary to use the scheme of cutting edge position in the basic plane, according to Fig. 10. 
Starting with the equation of ellipse 1 in coordinate system $x-y$ and ellipse 2 that represents the position of the tool after one turn, using substitutions, we obtained the relation for $R z$ :

$$
R z=r_{\varepsilon} \cdot \cos \gamma_{p}-\frac{1}{2 \cdot \cos \lambda_{\mathrm{s}}} \sqrt{4 \cdot r_{\varepsilon}^{2} \cdot \cos \lambda_{\mathrm{s}}-f^{2}}
$$

$R z$ depends on four parameters: $R z=f\left(r_{\varepsilon}, \gamma_{p}, \lambda_{\text {s }}, f\right)$, i.e. $r_{\varepsilon}$ tool tip radius (large), back rake angle $\gamma_{p}$, angle of cutting edge inclination $\lambda_{\mathrm{s}}$ and feed rate $f$. The Eq. (1) does not include cutting speed because it is not a geometric characteristic. Such dependence can be determined only experimentally.

Fig. 11 presents an example of the experimental dependence of the maximum height of profile $R z$ on tangential velocity of workpiece $v_{\mathrm{w}}$. This speed is not cutting speed (see Fig. 9).

At a low tangential velocity of workpiece $v_{\mathrm{w}}(5-45$ $\mathrm{m} / \mathrm{min}), R z$ values are within wide limits. At higher velocity (more than $45 \mathrm{~m} / \mathrm{min}$ ), $R z$ is almost constant in both cases of cutting tool position (above, under workpiece axis).

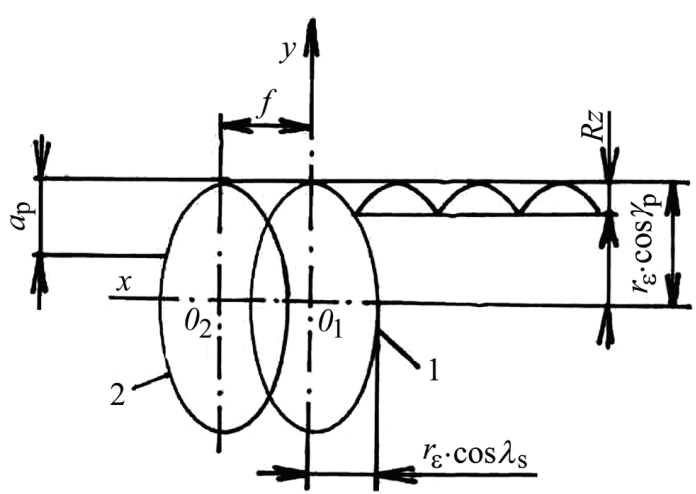

Figure 10 Schema for determination of $R z$ (1 and 2 - positions of tool after one turn)

\section{CONCLUSION}

The application of idea of straight cutting for machining of wooden workpieces shows the interesting perspective for turning of the composites with layers, fibres or combination. The hierarchical typology and oriented material properties of wood are similar to a typology of a fibre-layered composite. Moreover, the paper analyses the machining results obtained in turning by cutting tools with straight and quasi-straight (large tool tip radius) and confirms the suitability of such cutting tools for machining of natural fibre-layered composite, i.e. wood.

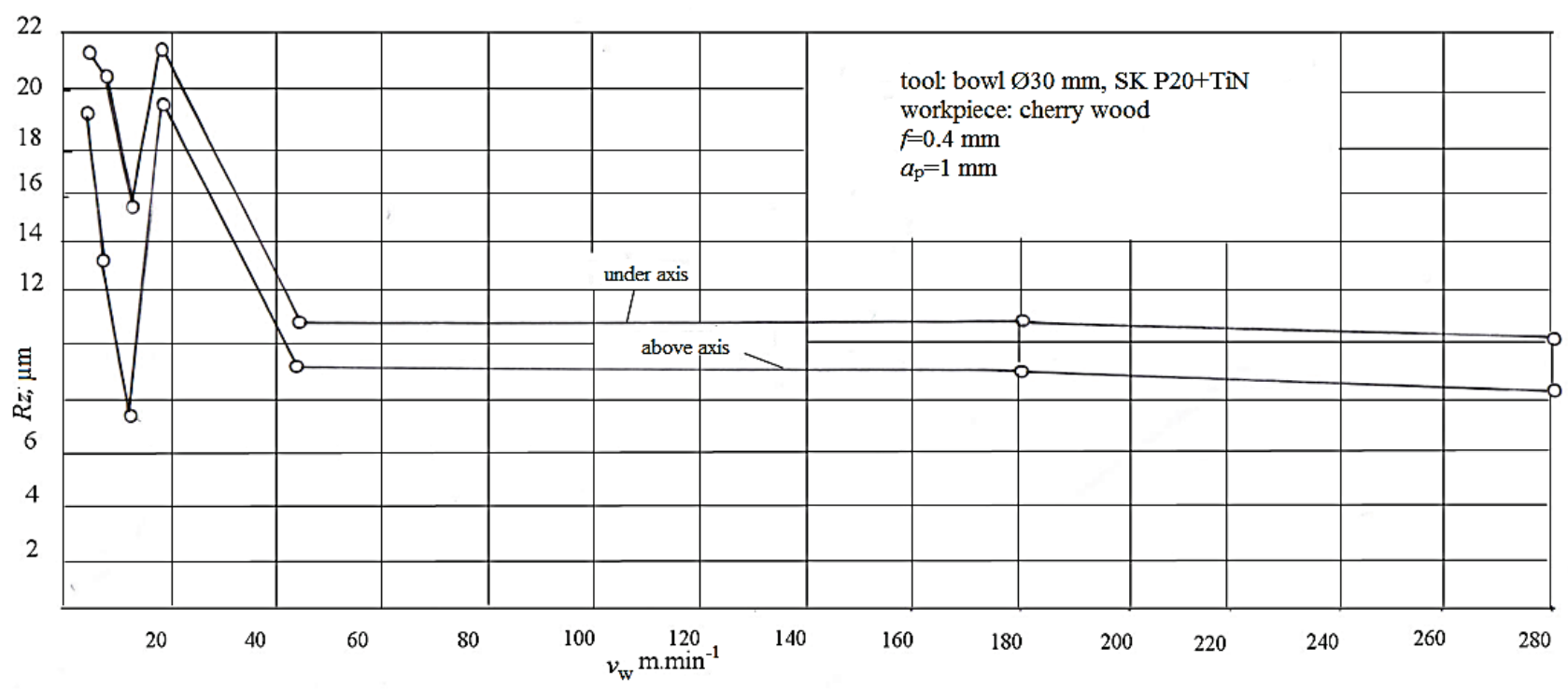

Figure 11 Experimental dependence of $R z=f\left(v_{\mathrm{w}}\right)$ for wood turning

\section{Acknowledgement}

Authors thank for supporting this research by grant VEGA 1/0910/17 of Agency of Ministry of Education of Slovak Republic.

\section{REFERENCES}

[1] Kahwash, F., Shyha, I., \& Maheri, A. (2015). Machining unidirectional composites using single-point tools: analysis of cutting forces, chip formation and surface integrity. Procedia Engineering, 132, 569-576. https://doi.org/10.1016/j.proeng.2015.12.534

[2] Lopresto, V., Caggiano, A., \& Teti, R. (2016). High performance cutting of fibre reinforced plastic composite materials. Procedia CIRP, 46, 71-82. https://doi.org/10.1016/j.procir.2016.05.079

[3] Gupta, M. \& Kumar, S. (2015). Investigation of surface roughness and MRR for turning of UD-GFRP using PCA and Taguchi method. Engineering Science and Technology, an International Journal, 18(1), 70-81. https://doi.org/10.1016/j.jestch.2014.09.006

[4] Oliveira, L. C., Jozsa, L., \& Western Dry Kiln Association. (1992). The structure of wood in relation to drying. http://workshopcompanion.com/KnowHow/Wood/ Hardwoods_\&_Softwoods/3_Physical_Properties/3_Physic al_Properties.htm

[5] Simunovic, G., Svalina, I., Simunovic, K., Saric, T., Havrlisan, S., \& Vukelic, D. (2016). Surface roughness assessing based on digital image features. Advances in Production Engineering \& Management, 11(2), 93-104. http://dx.doi.org/10.14743/apem2016.2.212 
[6] Borojevic, S., Lukic, D., Milosevic, M., Vukman, J., \& Kramar, D. (2018). Optimization of process parameters for machining of Al 7075 thin-walled structures. Advances in Production Engineering \& Management, 13(2), 125-135. https://doi.org/10.14743/apem2018.2.278

[7] Sung, A. N., Loh, W. P., \& Ratnam, M. M. (2016). Simulation Approach for Surface Roughness Interval Prediction in Finish Turning. International Journal of Simulation Modelling, 15(1), 42-55. https://doi.org/10.2507/IJSIMM15(1)4.320

[8] Vasilko, K. \& Pilc, J. (1980). Patent No. 211831. Klzné uloženie rotujúceho sústružníckeho noža (Sliding support of a rotating turning tool). Industrial Property Office of the Slovak Republic.

\section{Contact information:}

Karol VASILKO, Dr.h.c., Prof. MSc., DrSc.

Department of Manufacturing Technologies,

Faculty of Manufacturing Technologies,

Technical University of Košice,

Bayerova 1, 08001 Prešov, Slovak Republic

karol.vasilko@tuke.sk

Zuzana MURČINKOVÁ, Assoc. Prof., MSc., PhD.

(Corresponding author)

Department of Monitoring and Designing of Technical Systems,

Faculty of Manufacturing Technologies,

Bayerova 1,080 01 Prešov, Slovak Republic

zuzana.murcinkova@tuke.sk 